\title{
Optical pH imaging of concrete exposed to chemically corrosive environments
}

\author{
Cyrill Grengg ${ }^{1 *}$, Bernhard Mueller ${ }^{2}$, Florian Mittermayr ${ }^{3}$, Torsten Mayr ${ }^{3}$, Sergey Borisov ${ }^{2}$ \& Martin Dietzel ${ }^{1}$ \\ ${ }^{1}$ Institute of Applied Geosciences, Graz University of Technology, Rechbauerstraße 12, 8010 Graz, Austria \\ ${ }^{2}$ Institute of Analytical Chemistry and Food Chemistry, Graz University of Technology, Stremayrgasse 9/II, Graz, Austria \\ ${ }^{3}$ Institute of Technology and Testing of Building Materials, Graz University of Technology, Inffeldgasse 24, 8010 Graz, Austria
}

\begin{abstract}
Major types of chemical concrete degradation such as carbonation, leaching and acid attacks are strongly associated with decreasing internal or external $\mathrm{pH}$. Thus a precise determination of the latter is crucial for the assessment regarding the degree of corrosion and corresponding development of prevention strategies. Conventional $\mathrm{pH}$ measure methods for concrete, such as phenolphthalein indicator, pore solution extractions and flat surface electrodes have proven to contain significant limitations and inadequacies. This contribution presents the application of sensor foils based on luminescent $\mathrm{pH}$ sensitive dyes entrapped in a polymeric hydrogel matrix, to quantify and image the distribution of surface $\mathrm{pH}$ of concrete based construction materials. An imaging technique called time-domain dual lifetime referencing (t-DLR) was used, which suppresses artifacts from scattering of the background and other light inhomogeneities. Using this methodology high-resolution $\mathrm{pH}$ profiles of concrete samples exposed to carbonation and biogenic acid corrosion were recorded.
\end{abstract}

\section{Introduction}

The development of internal $\mathrm{pH}$ over time is a central parameter for the stability and durability of concrete structures. In general, the $\mathrm{pH}$ level in ordinary Portland cement based concretes is determined by the content of alkali metals, the addition of supplementary cementitious materials (SCMs) and curing conditions [1]. Thereby, the $\mathrm{pH}$ of fresh concrete is usually around 13 [2]. Due to concrete-environment interaction, change of $\mathrm{pH}$ is often initiated by concrete degradation. Major types of chemical concrete degradation such as chloride ingress, carbonation and acid attack are associated with decreasing internal or external $\mathrm{pH}$. In this context an accurate assessment and understanding of the $\mathrm{pH}$ development over time is critical for a holistic process understanding of these destructive reactions and the development of a tailored design of sustainable concrete based infrastructure. The state of the art on methods for $\mathrm{pH}$ assessment in hardened concrete has been recently summarized by Behnood et al. (2015), subcategorizing destructive and non-destructive approaches [3]. While destructive methods are centred around expression of interstitial concrete pore fluids and leaching methodologies, non-destructive research focused on the development of embedded sensors, such as potentiometric electrodes and fibre optics [4-6]. At the same time, limited methods exist for the high-resolution measurement of the spatial distribution of $\mathrm{pH}$ in concrete structures.
Since concrete is a multicomponent, porous material, $\mathrm{pH}$ change over time proceeds mostly non-linear. Thereby, the change of $\mathrm{pH}$ is strongly governed by the mineralogical heterogeneities within the concrete microstructure, differences in porosity and associated changing ion diffusion rates. In order to characterize this non-linear $\mathrm{pH}$ change during different concrete alteration processes, proper mapping techniques of the latter are required. To date, methodologies for measuring spatial $\mathrm{pH}$ distribution on concrete, although being crucial for the understanding of $\mathrm{pH}$ dependent degradation, are limited. The most frequently applied one is the application of phenolphthalein (PHPHT), a pH indicator, which is sprayed on a fresh concrete surface [7]. Recently, Liu et al. (2017) introduced a methodology for optical mapping of high $\mathrm{pH}$ levels (11.0-13.5) utilizing a halochromic porphyrin dye [8].

In this work we present a method for high-resolution $\mathrm{pH}$ imaging, demonstrated on concrete samples, which were pre-exposed to chemically aggressive environments. The $\mathrm{pH}$ imaging setup was realized by utilizing time-domain dual lifetime referencing (t-DLR) [9]. For this method a fluorescent $\mathrm{pH}$ indicator dye (short lifetime) is combined with a phosphorescent reference dye (long lifetime) with similar spectral properties. Both dyes are excitable with red light and emit in the near infrared part of the electromagnetic spectrum. Using this technique, we critically discuss decisive aspects of $\mathrm{pH}$ measurement, which have to be reconsidered for determining the $\mathrm{pH}$ of concrete structures.

\footnotetext{
* Cyrill Grengg: cyrill.grengg@tugraz.at
} 


\section{Methods}

\subsection{Sensor material}

The dye class of aza-BODIPYS is well known for their stability, their good near infrared emission and tuneable $\mathrm{pKa}$ value [10]. A dye with an apparent $\mathrm{pKa}$ value of 10.77 in solution was used for the measurements. AzaBODIPYS can be excited from $600 \mathrm{~nm}$ to $740 \mathrm{~nm}$, with its maximum being at $700 \mathrm{~nm}$, while emitting from $680 \mathrm{~nm}$ to $800 \mathrm{~nm}$. As reference dye Egyptian blue, a calcium copper silicate, was used. It is a ceramic material which exhibits excellent chemical and photochemical stability and shows near-infrared emission from around $800 \mathrm{~nm}-1000 \mathrm{~nm}$ [11]. It can be excited from $500 \mathrm{~nm}$ to $700 \mathrm{~nm}$ and exhibits no crosssensitivity to oxygen. Both dyes were suspended in $8 \%$ polymer solution of HydroMed D4 (purchased from Advanced Biomaterials) in THF/water $(9+1)$. The sensor formulation was knife coated on a $125 \mu \mathrm{m}$ thick PET foil from DuPont Teijin Films (Melimex 506), using a $3 \mathrm{mil}$ wet film knife from Byke. Accordingly, the thickness of the dry sensor film was approximately $6.1 \mu \mathrm{m}$. The concertation of aza-BODIPY within the sensor material was $0.2 \%$, and Egyptian Blue represents $33.3 \%$. The sensor foil was cut into a $4 \times 4 \mathrm{~cm}$ square, fitting the concrete samples, and stored in deionized water.

The sensor foil was calibrated using Goods buffer (TRIS, CHES, CAPS) at a concentration of $10 \mathrm{mM}$ and $\mathrm{NaCl}$ was used to adjust the ionic strength. The $\mathrm{pH}$ of the buffer solutions was altered with $\mathrm{NaOH}$ or $\mathrm{HCl}$, respectively. The sensor foil was soaked in buffer, pictures were taken and the ratiometric value of the area of interest plotted against the respective $\mathrm{pH}$ value. Data was fitted with the Bolzmann equation to gain the calibration curve (see Figure 2).

\subsection{Concrete}

A pre-carbonated, high performance concrete building block, corresponding to class B6 (C25/30/XC4/XD2/XF3/XA2UXA2TISB) according to standard regulations (EN-206-1), was cut in $1 \mathrm{~cm}$ thick concrete slices with the dimension of $4 \times 4 \mathrm{~cm}$, using an angle grinder. Subsequently the specimens were outsourced for 30 days into a sewer system, strongly affected by biogenic acid corrosion. After sample collection, concrete specimens were dried at $40^{\circ} \mathrm{C}$ for $24 \mathrm{~h}$. On each sample 4 reference $\mathrm{pH}$ measurements were conducted using a Extech PH100 flat surface electrode.

\subsection{Imaging setup}

For excitation the power LED array LR CP7P from OSRAM Opto Semiconductors $\mathrm{GmbH}$, with a maximal emission wavelength of $625 \mathrm{~nm}$, was used. It was operated with a constant current of $200 \mathrm{~mA}$ provided by the DC power supply DF1730SL from Ningbo Jinyaun (G.S) Electricity Co. In order to generate constant light pulses, a pre-resistor with $3.9 \Omega$ was used.

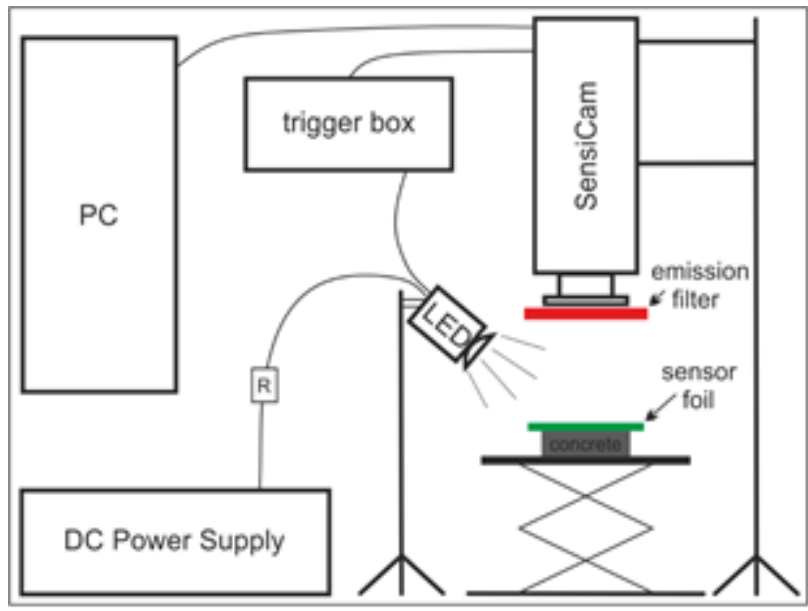

Fig. 1. Schematic description of the surface $\mathrm{pH}$ imaging setup.

A RG9 emission filter from Schott, with a transparent window from $700-1000 \mathrm{~nm}$, was placed in front of the time-gate able SensiCam from PCO AG for collecting NIR images. The time coordination between these two devices was realized by a trigger box from Biocam $\mathrm{GmbH}$. A schematic view of the imaging setup is presented in Fig. 1.

The surface $\mathrm{pH}$ of concrete samples was imaged by placing the wet, calibrated sensor foil onto the samples. Air pockets were eliminated by striking gently across the foil and two consecutive pictures were taken after 1 minute. The first was recorded during the excitation phase ("light-on"), where both dyes contribute to the image; the second one right after the excitation ("lightoff'), where only the reference dye is emitting. The images were divided through each other utilizing a python script to gain the ratiometric image.

\section{Results and Discussion}

The aim of this study was to explore t-DLR as an imaging technique for concrete based materials in order to gain a better understanding of ongoing processes and to critically discuss state of the art measurements like flat surface electrodes.

A successful calibration curve of the sensor foil was obtained using the Boltzmann equation as fitting function (Fig. 2). The resulting Boltzmann sigmoid has its point of inflection (V50) at a $\mathrm{pH}$ value of 10.69 , representing the apparent $\mathrm{pKa}$ value of the sensor foil. As expected, this matches closely the $\mathrm{pKa}$ value of the aza-BODIPY dye in solution at 10.77 . The sensitive range of the sensor foil therefore starts around $\mathrm{pH} 9$ and 


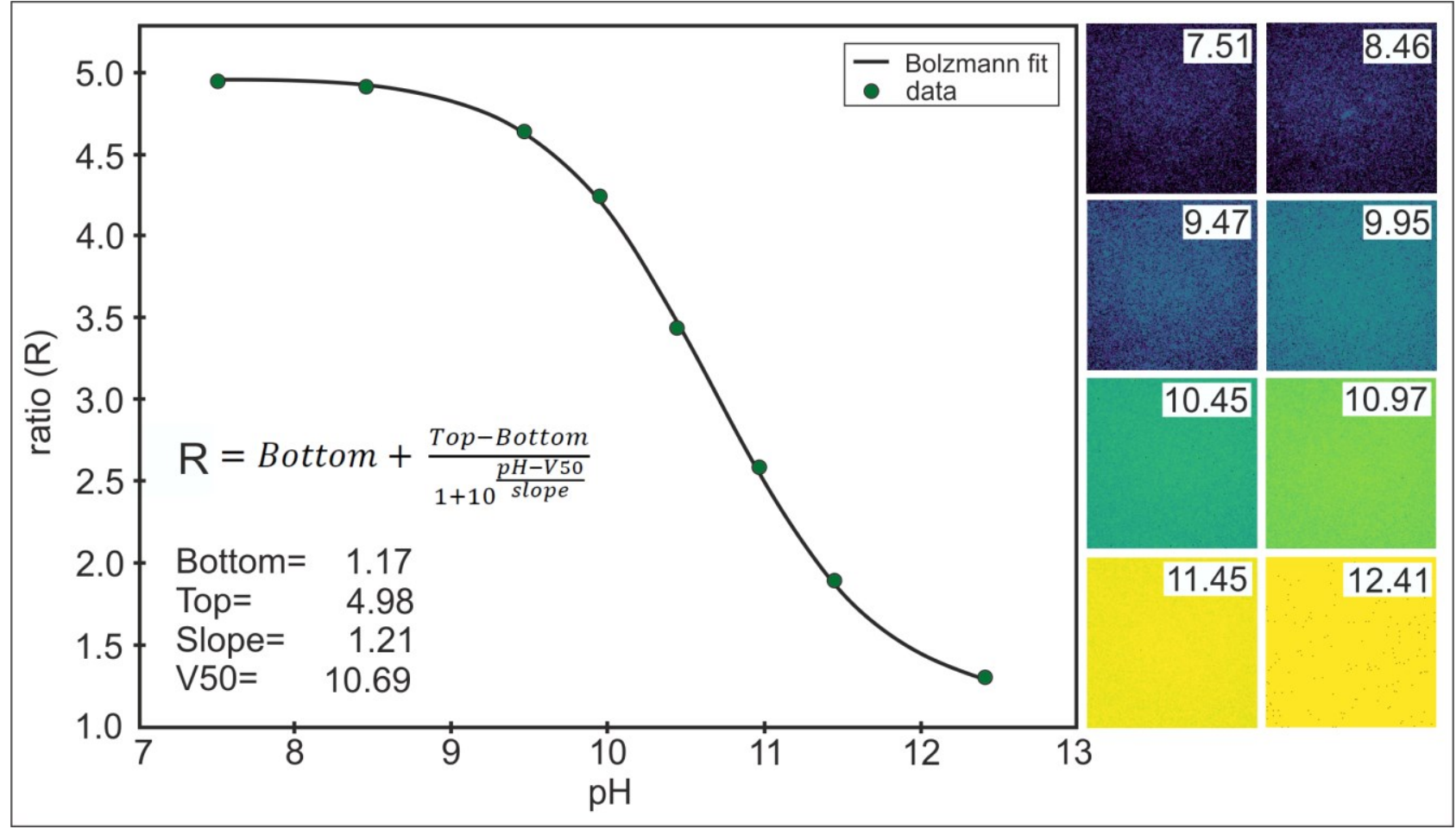

Fig. 2. Calibration curve of the used sensor foil with fitted parameters and ratiometric images of the buffer soaked sensor foil at the different $\mathrm{pH}$ values.

goes up to $\mathrm{pH} 12$. For image processing the $\mathrm{pH}$ from 8.8 to 11.5 was visualized to cover the most interesting area of the concrete specimens with high-resolution.

Accordingly, high-resolution surface $\mathrm{pH}$ images of different concrete specimen were obtained and subsequently compared to spot $\mathrm{pH}$ measurement of the same concrete surfaces, conducted by flat surface electrodes (Fig. 3).

In general, a similar $\mathrm{pH}$ was observed with both applied methods. Obviously the imaging technique allows the visualization of $\mathrm{pH}$ gradients along the concrete surface with a high spatial resolution in a $\mathrm{pH}$ range from 8.8 to
11.5. This enables to resolve the influence of the heterogenic mineralogy of the concrete specimens. An inhomogeneous, gradual decrease in $\mathrm{pH}$ is visible within the cementitious matrix of rim areas due to progressive carbonation of the cementitious matrix, while a generally high $\mathrm{pH}$ remains within the core areas. These variations cannot be captured using flat surface electrodes. Especially within chemically aggressive systems, a detailed understanding of the internal $\mathrm{pH}$ is crucial in order to determine the degree of degradation and to increase process understanding of the latter.
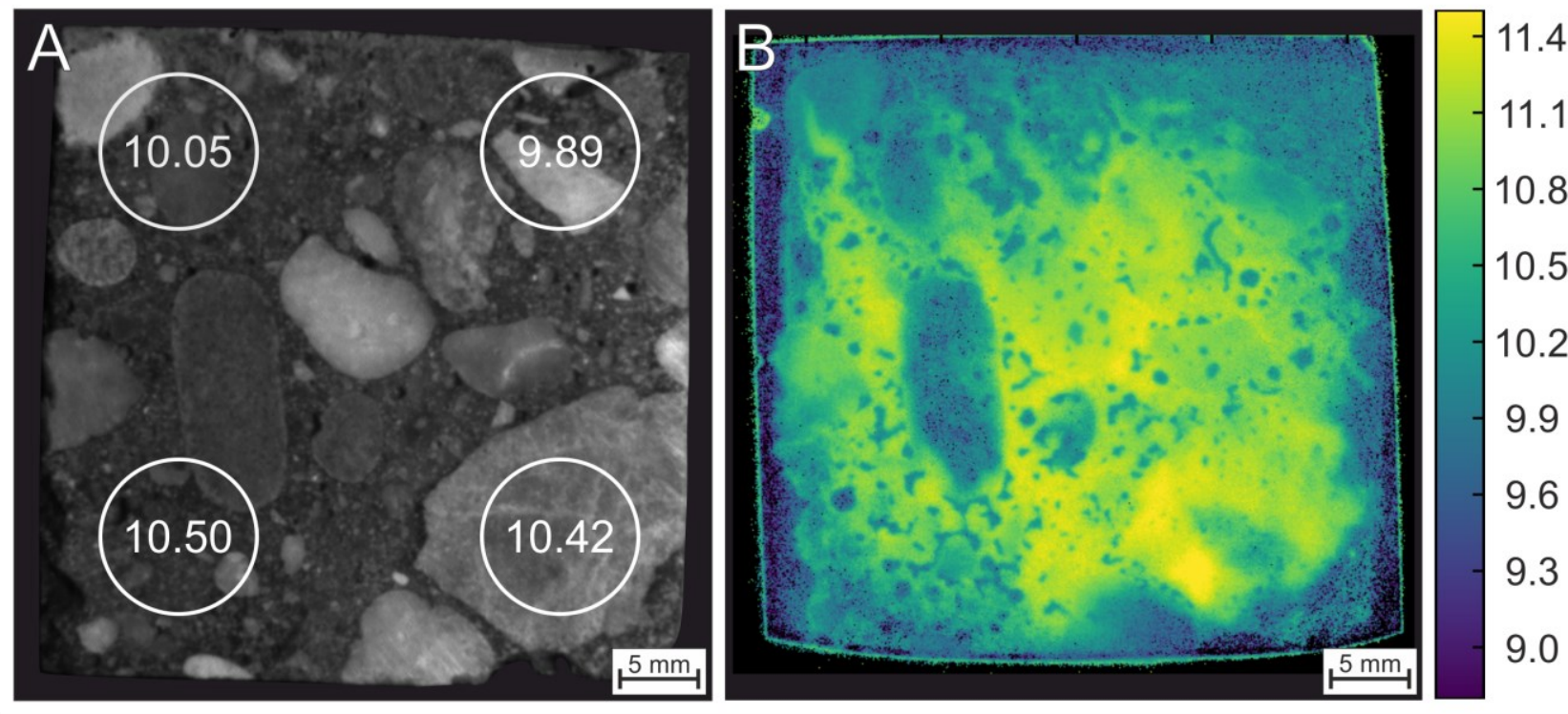

Fig. 3. A) Image of a concrete sample with reference $\mathrm{pH}$ values obtained with a flat surface electrode. B) Ratiometric image of the same sample showing the $\mathrm{pH}$ distribution on the surface with a resolution from $\mathrm{pH} 8.8$ to 11.5 
In this context, the informative value of spot analyses as a proxy for the determination of corrosion progress should be seen critical, while the applied imaging technique exhibit high potential for such applications.

\section{Conclusion \& Outlook}

The reference $\mathrm{pH}$ measurement with the flat surface electrode verified the high-resolution $\mathrm{pH}$ images to be robust and truly represent the $\mathrm{pH}$ of the concrete surface. We therefore conclude, that the t-DLR pH imaging setup provides a viable tool for gaining a deeper knowledge about ongoing destructive surface processes of heterogenic, porous concrete samples. Furthermore, the setup described herein can significantly contribute towards an increased understanding in respect to crucial unanswered questions regarding the impact of diffusion (horizontally and vertically) driven $\mathrm{pH}$ drifts during measurements and the impact of porosity and material heterogeneities. Corresponding ongoing research aspects will be presented and discussed.

\section{References}

1. Plusquellec G, Geiker MR, Lindgård J, et al (2017) Determination of the $\mathrm{pH}$ and the free alkali metal content in the pore solution of concrete: Review and experimental comparison. Cem Concr Res 96:13-26. doi: 10.1016/j.cemconres.2017.03.002

2. Alexander M, Bertron A, De Belie N (2013) Performance of Cement-Based Materials in Aggressive Aqueous Environments, 1st ed. doi: 10.1007/978-94-007-5413-3

3. Behnood A, Van Tittelboom K, De Belie N (2016) Methods for measuring $\mathrm{pH}$ in concrete: A review. Constr Build Mater 105:176-188. doi: 10.1016/j.conbuildmat.2015.12.032
4. Safavi A, Bagheri M (2003) Novel optical pH sensor for high and low $\mathrm{pH}$ values. Sensors Actuators, B Chem Actuators 90:143-150.

5. Pásztor K, Sekiguchi A, Shimo N, et al (1993) Iridium oxide-based microelectrochemical transistors for $\mathrm{pH}$ sensing. Sensors Actuators B Chem 12:225230. doi: 10.1016/0925-4005(93)80023-5

6. Wolfbeis OS (2004) Fiber-Optic Chemical Sensors and Biosensors. Anal Chem 76:3269-3284. doi: $10.1021 / \mathrm{ac} 040049 \mathrm{~d}$

7. Parrott LJ (1987) A Review of carbonation in reinforced concrete. Springer, Wexham Springs, Slough; Garston, Watford

8. Liu E, Ghandehari M, Brückner C, et al (2017) Mapping high $\mathrm{pH}$ levels in hydrated calcium silicates. Cem Concr Res 95:232-239. doi: 10.1016/j.cemconres.2017.02.001

9. Schröder CR, Weidgans BM, Klimant I (2005) pH Fluorosensors for use in marine systems. Analyst 130:907. doi: 10.1039/b501306b

10. Strobl M, Rappitsch T, Borisov SM, et al (2015) NIR-emitting aza-BODIPY dyes - new building blocks for broad-range optical $\mathrm{pH}$ sensors. Analyst 140:7150-7153. doi: 10.1039/C5AN01389E

11. Borisov SM, Würth C, Resch-Genger U, Klimant I (2013) New life of ancient pigments: Application in high-performance optical sensing materials. Anal Chem 85:9371-9377. doi: 10.1021/ac402275g 